\title{
Superação de dormência em sementes de Leucaena leucocephala (Lam.) de Wit. com métodos físicos e químicos
}

\section{Dormancy overcoming of Leucaena leucocephala (Lam.) Wit. seeds with physical and chemical methods}

\author{
Allysson Jonhnny Torres Mendonça ${ }^{1}$; Marcelo Cleón de Castro Silva ${ }^{2}$; Franklyn Hugo Ramalho Berto ${ }^{1}$; \\ Ancélio Ricardo de Oliveira Gondim ${ }^{2}$; Mizael Nabor Vaz de Medeiros ${ }^{1}$; Weslley Lima Lins ${ }^{3}$
}

${ }^{1}$ Graduando em Agronomia na Universidade Federal de Campina Grande, Campus Pombal, Paraíba. +5583981331784. allyssonjonhnny@hotmail.com; franklynhugo@hotmail.com; mizaeldemedeiros@hotmail.com; ${ }^{2}$ Professor na Universidade Federal de Campina Grande, Campus Pombal, Paraíba; marcelo.castro@ufcg.edu.br; ancelio.gondim@ccta.ufcg.edu.br. ${ }^{3}$ Graduando em Engenharia Ambiental na Universidade Federal de Campina Grande, Campus Pombal, Paraíba, weslleylins7@gmail.com.

N O T A

Recebido: $16 / 03 / 2020$

Aprovado: $17 / 06 / 2020$

\section{Palavras-chave:}

Leguminosa

Adubo verde

Escarificação

Germinação

Viabilidade

\section{Key words}

Legume plant

Green manure

Scarification

Germination

Viability

\section{R E S U M O}

A leucena é uma espécie florestal que proporciona forragem de boa qualidade e, pode ser utilizada como adubo verde, porém, suas sementes apresentam dormência causada pela impermeabilidade do tegumento à água, provocando redução na germinação, o que dificulta a produção de mudas. O objetivo deste trabalho foi avaliar a superação de dormência em sementes de leucena por métodos físicos e químicos. O delineamento experimental foi o inteiramente casualizado com quatro repetições composto por 20 sementes em cada tratamento. Utilizou-se como tratamentos químicos a imersão das sementes em ácido sulfúrico concentrado durante 1, 2, 4, 6, 8 e 10 minutos. Os tratamentos físicos usados foram o desponte (corte com estilete em lado oposto à micrópila), a escarificação com lixa d'agua $\mathrm{n}^{\circ} 80$ e a escarificação com lixa d'agua $\mathrm{n}^{\mathrm{o}} 100$ (nestes dois últimos tratamentos lixou-se a semente em lado oposto à micrópila), tendo também o tratamento testemunha (sem intervenção). Avaliou-se o índice de velocidade de germinação, tempo médio de germinação, percentagem de germinação por um período de 10 dias após o semeio, altura de plântula, comprimento da raiz, diâmetro do caule, matéria fresca e seca da parte aérea e matéria fresca e seca da raiz. O método mais adequado para superar a dormência em sementes de leucena é o uso da escarificação com lixa d'água $n^{\circ}$ 100.

\section{A B S T R A C T}

Leucena is a forest species that provides good quality forage and can be used as green manure, however, its seeds present dormancy caused by the impermeability of the seed coat to water, causing reduction in germination, which makes seedling production difficult. It was aimed evaluate the overcome of dormancy in leucena seeds by physical and chemical methods. The experimental design was completely randomized with four replications consisting of 20 seeds in each treatment. Chemical immersion of the seeds in concentrated sulfuric acid for 1, 2, 4, 6, 8 and 10 minutes was used as chemical treatments. The physical treatments used were topping (cutting with a stylus on the opposite side to the micropyle), scarification with sandpaper $n^{\circ} 80$ and scarification with sandpaper $\mathrm{n}^{\circ} 100$ (in these last two treatments, the seed was sanded on the opposite side to the micropyle), also having the control treatment (without intervention). The germination speed index, average germination time, percentage of germination for a period of 10 days after sowing, seedling height, root length, stem diameter, fresh and dry matter of the shoot and fresh matter were evaluated and dry the root. The most suitable method to overcome dormancy in leucena seeds is the use of scarification with sandpaper $\mathbf{n}^{\mathbf{0}} 100$.

\author{
Revista Verde \\ ISSN 1981-8203 \\ Pombal, Paraíba, Brasil
}

v. 15, n.3, jul.-set., p.325-329, 2020 doi: $10.18378 /$ rvads.v15i3.7754 


\section{INTRODUÇÃO}

A leucena é uma espécie leguminosa forrageira $\mathrm{e}$ madeireira que se adapta a regiões tropicais (OSECHAS et al., 2008; COSTA e DURIGAN, 2010; SILVA et al., 2012). Além desses usos, essa planta é utilizada como cobertura morta vegetal por ser fixadora de nitrogênio ao solo proporcionando adubo verde para cultivos agrícolas, bem como pode ser usada para recuperar áreas degradadas (HALLIDAY et al., 2013).

O plantio de leucena é realizado com o uso de mudas de qualidade, porém, verifica-se nas sementes dessa espécie um fenômeno natural fisiológico denominado dormência, devido à impermeabilidade do tegumento. Segundo Cardoso et al. (2012) ocorre na semente dessa leguminosa o impedimento de absorção de água que impõe a restrição mecânica e o crescimento do embrião, que visa perpetuar a espécie vegetal no tempo e no espaço. Fatores internos como longevidade e viabilidade e, externos como condições ambientais, afetam a germinação (OLIVEIRA, 2008).

Para superar a dormência nas sementes é necessário alterar a estrutura no tegumento da leucena com métodos físicos (uso de lâminas, limas, lixas) e químicos (ácidos e solventes) para obter uma germinação elevada e bom desenvolvimento de plântulas (ALVES et al., 2007).

Pesquisas com sementes de Leucaena leucocephala (Lam.) de Wit. e Adenanthera pavonina L. têm verificado que o método que se destaca-se na germinação dessas espécies florestais, é a escarificação mecânica por ser simples e segura. (HERMANSEN et al., 2000; TELES et al., 2000; RIBEIRO et al., 2009).

Segundo Oliveira e Medeiros Filho (2007) a não submissão de tratamentos para a superação do tegumento inviabiliza a produção de mudas já que os resultados da germinação são menores que 50\%, proporcionando dessa forma prejuízo econômico ao agricultor.

Neste contexto, o objetivo deste trabalho foi avaliar a superação de dormência em sementes de leucena com métodos físicos e químicos.

\section{MATERIAL E MÉTODOS}

$\mathrm{O}$ experimento foi realizado em casa de vegetação na Universidade Federal de Campina Grande -campus Pombal PB, no mês de agosto de 2017. Com clima quente e seco, o município se caracteriza pela insuficiência de chuvas, com precipitação pluvial anual média de $700,0 \mathrm{~mm}$ e temperaturas elevadas apresentando temperatura anual média de $30,5^{\circ} \mathrm{C}$, com umidade relativa do ar anual média de $48,0 \%$, tendo apenas duas estações climáticas bem definidas durante o ano, uma chuvosa e outra seca.

As sementes de leucena foram coletadas diretamente de árvores-matrizes na Caatinga paraibana por meio de debulha, realizada em julho de 2017 e armazenadas em geladeira, à temperatura de $5^{\circ} \mathrm{C}$.

$\mathrm{O}$ delineamento experimental utilizado foi o inteiramente casualizado, constando quatro repetições composta de 20 sementes por tratamento. Após o beneficiamento as sementes foram submetidas aos seguintes tratamentos químicos com a imersão das sementes em ácido sulfúrico concentrado durante 1 , $2,4,6,8$ e 10 minutos e, os tratamentos físicos usados foram o desponte (corte com estilete em lado oposto à micrópila), a escarificação com lixa d'agua $n^{\circ} 80$ e a escarificação com lixa d'agua $\mathrm{n}^{\mathrm{o}} 100$ (nestes dois últimos tratamentos lixou-se a semente em lado oposto à micrópila), tendo também o tratamento testemunha (sem intervenção).

Após aplicação dos tratamentos nas sementes com ácido sulfúrico, foram lavadas em água corrente para tirar o excesso do ácido e, em seguida foram imersas em solução de hipoclorito de sódio a $5 \%$ por 5 minutos e, em seguida foram lavadas com água destilada e semeadas.

O semeio ocorreu em bandejas de poliestireno no dia 28 de agosto a $1 \mathrm{~cm}$ de profundidade, tendo como substrato a areia peneirada e esterilizada em autoclave por um período de 60 minutos a uma temperatura de $120^{\circ} \mathrm{C}$. Realizaram-se irrigações diárias para manter a umidade adequada à germinação das sementes.

Foram realizadas avaliações diárias por um período de 10 dias após o semeio para verificar a percentagem de germinação, o índice de velocidade de germinação pelo somatório do número de sementes germinadas $(\mathrm{G} 1, \mathrm{G} 2, \mathrm{G} 3, \ldots, \mathrm{Gn})$ a cada dia, dividido pelo número de dias decorridos $(\mathrm{N} 1, \mathrm{~N} 2, \mathrm{~N} 3, \ldots$, $\mathrm{Nn})$ entre a semeadura e a germinação, de acordo com a fórmula de MAGUIRE (1962) e, o tempo médio de germinação conforme Laboriau (1983).

Considerou-se germinadas as sementes que emitiram parte aérea com pelo menos duas folhas bem desenvolvidas, e mortas as sementes que não emitiram parte aérea. Como também aos 10 dias após a semeadura (DAS) foram avaliados: altura de plântula, determinada do colo até à inserção da última folha, com auxílio de régua; diâmetro de caule, por meio de paquímetro; comprimento de raiz, com uso de régua; matéria fresca e seca de parte aérea e matéria fresca e seca de raiz, realizadas por meio de balança. O peso de matéria seca da parte aérea e raiz foram realizados após acondicionamento das partes da planta em estufa com circulação forçada de ar à temperatura de $65^{\circ} \mathrm{C}$ até atingirem peso constante.

Os dados foram submetidos à análise de variância, utilizando-se o teste $\mathrm{F}(\mathrm{p} \leq 0,05)$, sendo as médias comparadas pelo teste de Tukey $(\mathrm{p} \leq 0,05)$, com o auxílio do programa computacional SISVAR (FERREIRA, 2008).

\section{RESULTADOS E DISCUSSÃO}

De acordo com os dados da Tabela 1 que nas três variáveis verifica-se que ocorreu diferença significativa entre os tratamentos avaliados. Para percentagem de germinação os maiores valores foram encontrados quando utilizou-se a imersão de sementes em ácido sulfúrico concentrado durante 6 , 8 e 10 minutos, desponte e, escarificação com lixa d'agua $\mathrm{n}^{\circ} 80$ e $n^{\circ} 100$. Na característica IVG percebe-se que a imersão de sementes em ácido sulfúrico concentrado durante 10 minutos e a escarificação com lixa d'agua $\mathrm{n}^{\circ} 100$ proporcionaram os melhores resultados. Em tempo médio de germinação constatase os maiores valores quando se utilizou a testemunha e, as imersões de sementes em ácido sulfúrico concentrado durante 1, 2,4 e 5 minutos. 
Tabela 1. Médias de percentagem de germinação (PEG), índice de velocidade de germinação (IVG) e tempo médio de germinação (TMG) de sementes de leucena submetidas a tratamentos físicos e químicos.

\begin{tabular}{cccc}
\hline Tratamentos & PEG $(\%)$ & IVG & TMG (dias) \\
\hline 1 & $10,00 \mathrm{~d}^{*}$ & $0,2775 \mathrm{f}$ & $9,50 \mathrm{a}$ \\
2 & $40,00 \mathrm{c}$ & $0,7350 \mathrm{ef}$ & $8,80 \mathrm{a}$ \\
3 & $42,00 \mathrm{c}$ & $1,0600 \mathrm{ef}$ & $8,60 \mathrm{a}$ \\
4 & $71,25 \mathrm{~b}$ & $1,4000 \mathrm{de}$ & $8,30 \mathrm{a}$ \\
5 & $81,25 \mathrm{ab}$ & $2,0825 \mathrm{~d}$ & $8,88 \mathrm{a}$ \\
6 & $91,25 \mathrm{ab}$ & $3,1650 \mathrm{c}$ & $6,68 \mathrm{~b}$ \\
7 & $97,50 \mathrm{a}$ & $4,2450 \mathrm{a}$ & $5,15 \mathrm{~d}$ \\
8 & $91,25 \mathrm{ab}$ & $3,2500 \mathrm{~b}$ & $6,50 \mathrm{bc}$ \\
9 & $93,75 \mathrm{a}$ & $3,3825 \mathrm{bc}$ & $5,43 \mathrm{~cd}$ \\
10 & $97,50 \mathrm{a}$ & $4,1250 \mathrm{ab}$ & $5,50 \mathrm{bcd}$ \\
\hline C.V. $(\%)$ & 12,67 & 14,55 & 7,01
\end{tabular}

*Médias seguidas pela mesma letra na coluna não diferem entre si pelo teste de Tukey $(\mathrm{P}<0,05) .1$ - Testemunha; 2- Imersão de sementes em ácido sulfúrico concentrado durante 1 minuto; 3 - Imersão de sementes em ácido sulfúrico concentrado durante 2 minutos; 4 - Imersão de sementes em ácido sulfúrico concentrado durante 4 minutos; 5 - Imersão de sementes em ácido sulfúrico concentrado durante 6 minutos; 6 - Imersão de sementes em ácido sulfúrico concentrado durante 8 minutos; 7 - Imersão de sementes em ácido sulfúrico concentrado durante 10 minutos; 8 - Desponte; 9 - Escarificação com lixa d'agua $\mathrm{n}^{\circ} 80$ e 10 - Escarificação com lixa d'agua n ${ }^{\circ} 100$.

Araújo et al., (2012) pesquisaram a germinação em sementes de leucena sob diferentes tratamentos físicos e químicos, perceberam que a maior percentagem de germinação foi obtida nos tratamentos com escarificação pela lima, água quente a $80^{\circ} \mathrm{C}$ por 5 minutos e, em água quente a $100^{\circ} \mathrm{C}$ seguida de imersão em água na temperatura ambiente (choque térmico), dessa forma, obtiveram os seguintes resultados, 91,00, 89,50 e $70,00 \%$, respectivamente. Na característica índice de velocidade de germinação estes mesmos pesquisadores encontraram o maior valor $(6,40)$ quando se experimentou o tratamento com escarificação com lima. Segundo Perez (2004) a imersão em ácido sulfúrico provoca o desgaste do tegumento, acarretando a permeabilidade de água na semente, o que provavelmente proporcionou valores elevados de percentagem de germinação e índice de velocidade de germinação e, baixos resultados de tempo médio de germinação, esse método embora seja satisfatório é, considerado perigoso devido o manuseio de produto químico e prejudicial ao meio ambiente. Quanto aos tratamentos com escarificações com lixas, embora, tenham sido eficientes, tem-se a desvantagem devido o uso de grande mão de obra nesse procedimento, o que torna o custo elevado, principalmente quando utiliza-se alta quantidade de sementes, contudo, não é um método que provoca poluição ambiental.

Pesquisa realizada por Oliveira e Medeiros Filho (2007) em sementes de leucena verificou que se não for realizado algum tipo de tratamento para quebra de dormência, ocorrerá uma baixa germinação nas sementes dessa espécie, valores estes inferiores a 50\%, tornando inviável a produção de mudas, informações estas que corroboram com os resultados desse trabalho, provando que ocorre nessa espécie vegetal uma dormência tegumentar natural.

Para Luz e Nunes, (2013) sementes de leguminosas necessitam de procedimentos adequados para a quebra de dormência e, que a escarificação com lixa e imersão de sementes em água a $80^{\circ} \mathrm{C}$ apresentam melhores resultados para boa percentagem de germinação. Também Carrijo et al., (2008) comprovaram a eficácia do uso de escarificação mecânica promovida por lixa para superar a dormência em sementes de leucena.

Trabalhando com sementes de braúna (Schinopsis brasiliense) submetidas a diferentes métodos de escarificação Alves et al. (2007) verificaram que para as características percentagem de germinação e índice de velocidade de germinação as sementes que obtiveram os maiores valores foram as tratadas com escarificação mecânica com lixa A40 pano metal. Na característica tempo médio de germinação estes autores observaram que os menores valores foram encontrados quando as sementes foram submetidas aos tratamentos com imersão em água quente a $80^{\circ} \mathrm{C}$, testemunha e escarificação com lixa A40 pano metal, não diferindo estatisticamente os valores desta característica para estes três tratamentos. Dessa forma, percebe-se que o tratamento com lixa proporciona bons resultados na germinação de sementes, o que corrobora os encontrados nessa pesquisa, sendo que ambas pertencem à mesma família botânica leguminosa.

Oliveira (2009) estudando a influência de tratamentos prégerminativos em sementes de leucena obteve o maior tempo médio de germinação quando as sementes foram imersas em água quente a $100^{\circ} \mathrm{C} \mathrm{e}$, o menor tempo médio de germinação foi verificado em sementes escarificadas com ácido sulfúrico a $98 \%$ por 10 minutos com 5,8 e 2,4 dias, respectivamente, resultados estes que refutam os encontrados nessa pesquisa.

Verifica-se na Tabela 2, que em todas as características avaliadas ocorreram diferença estatística significativa quando utilizou-se os tratamentos para supressão de dormência em sementes de leucena. Na característica Altura de plântula os tratamentos físicos, desponte, escarificação com lixa d'agua $\mathrm{n}^{\circ}$ 80 e escarificação com lixa d'agua $\mathrm{n}^{0} 100$ proporcionaram maiores valores desta característica, embora não tenha diferido dos tratamentos imersão de sementes em ácido sulfúrico concentrado durante 8 minutos e imersão de sementes em ácido sulfúrico concentrado durante 10 minutos.

Em diâmetro de caule todos os tratamentos proporcionaram os maiores valores para esta característica (Tabela 2), exceto a imersão de sementes em ácido sulfúrico concentrado durante 8 minutos e o desponte. Para o comprimento de raiz os tratamentos imersão de sementes em ácido sulfúrico concentrado durante 10 minutos, desponte e escarificação com lixa d'agua $n^{\circ} 80$ evidenciaram os maiores resultados, porém, não diferiram estatisticamente dos valores proporcionados dos tratamentos imersão de sementes em ácido sulfúrico concentrado durante 2 minutos, imersão de sementes em ácido sulfúrico concentrado durante 4 minutos, imersão de sementes em ácido sulfúrico concentrado durante 6 minutos, imersão de sementes em ácido sulfúrico concentrado durante 8 minutos e escarificação com lixa d'agua $\mathrm{n}^{\circ} 100$.

Para matéria fresca da parte aérea os maiores valores foram verificados quando se aplicou-se os tratamentos imersão de sementes em ácido sulfúrico concentrado durante 4 minutos, imersão de sementes em ácido sulfúrico concentrado durante 10 minutos e os tratamentos físicos (desponte, escarificação com lixa d'agua $n^{\circ} 80$ e escarificação com lixa d'agua $n^{0} 100$ ), embora não tenha diferenciado estatisticamente dos valores dos 
tratamentos imersão de sementes em ácido sulfúrico concentrado durante 2 minutos, imersão de sementes em ácido sulfúrico concentrado durante 6 minutos e imersão de sementes em ácido sulfúrico concentrado durante 8 minutos (Tabela 2).

Quanto à matéria seca da parte aérea os maiores valores ocorreram quando utilizou-se os tratamentos desponte, escarificação com lixa d'agua $n^{\circ} 80$ e escarificação com lixa d'agua $\mathrm{n}^{\circ} 100$. Na característica matéria fresca da raiz o maior valor foi encontrado quando aplicou-se escarificação com lixa d'agua $n^{\circ} 80$. Em matéria seca da raiz percebe-se que os maiores valores foram verificados quando utilizou-se os tratamentos imersão de sementes em ácido sulfúrico concentrado durante 4 minutos, imersão de sementes em ácido sulfúrico concentrado durante 8 minutos, imersão de sementes em ácido sulfúrico concentrado durante 10 minutos, desponte, escarificação com lixa d'agua $n^{\circ} 80$ e escarificação com lixa d'agua $n^{\circ} 100$, mas não diferiu dos resultados proporcionado pelos tratamentos imersão de sementes em ácido sulfúrico concentrado durante 2 minutos e imersão de sementes em ácido sulfúrico concentrado durante 6 minutos (Tabela 2).

Tabela 2. Médias de altura de plântula (ALTP, cm), diâmetro de caule (DIAC, mm), comprimento de raiz (COMR, cm), matéria fresca de parte aérea (MFPA, g), matéria seca de parte aérea (MSPA, g), matéria fresca de raiz (MFRA, g) e matéria seca de raiz (MSRA, g) provenientes do semeio de sementes de leucena submetidas a tratamentos físicos e químicos.

\begin{tabular}{|c|c|c|c|c|c|c|c|}
\hline Tratamentos & ALTP & DIAC & COMR & MFPA & MSPA & MFRA & MSRA \\
\hline 1 & $2,07 \mathrm{e}^{*}$ & $1,47 \mathrm{a}$ & $3,97 \mathrm{de}$ & $0,1001 \mathrm{e}$ & $0,0263 \mathrm{c}$ & $0,0029 \mathrm{e}$ & $0,0027 \mathrm{~d}$ \\
\hline 2 & $2,53 \mathrm{~d}$ & $1,29 \mathrm{ab}$ & $3,57 \mathrm{e}$ & $0,1243 \mathrm{~d}$ & $0,0257 \mathrm{c}$ & $0,0034 \mathrm{e}$ & $0,0030 \mathrm{~cd}$ \\
\hline 3 & $2,56 \mathrm{~d}$ & $1,33 \mathrm{ab}$ & $4,08 \mathrm{bcd}$ & $0,1365 \mathrm{~cd}$ & $0,0262 \mathrm{c}$ & $0,0055 \mathrm{~cd}$ & $0,0044 \mathrm{bcd}$ \\
\hline 4 & $2,63 \mathrm{~d}$ & $1,25 \mathrm{ab}$ & $4,49 \mathrm{bcd}$ & $0,1469 \mathrm{abc}$ & $0,0267 \mathrm{bc}$ & $0,0056 \mathrm{~cd}$ & $0,0047 \mathrm{abcd}$ \\
\hline 5 & $2,77 \mathrm{~d}$ & $1,14 \mathrm{ab}$ & $4,63 \mathrm{bd}$ & $0,1362 \mathrm{~cd}$ & $0,0257 \mathrm{c}$ & $0,0049 \mathrm{de}$ & $0,0040 \mathrm{bcd}$ \\
\hline 6 & $3,24 \mathrm{c}$ & $1,08 \mathrm{~b}$ & $4,12 \mathrm{bcd}$ & $0,1405 \mathrm{bcd}$ & $0,0275 \mathrm{bc}$ & $0,0079 \mathrm{ab}$ & $0,0055 \mathrm{abcd}$ \\
\hline 7 & $3,36 \mathrm{bc}$ & $1,21 \mathrm{ab}$ & $5,97 \mathrm{a}$ & $0,1637 \mathrm{a}$ & $0,0321 \mathrm{~b}$ & $0,0070 \mathrm{bc}$ & $0,0058 \mathrm{abcd}$ \\
\hline 8 & $3,68 \mathrm{abc}$ & $1,12 \mathrm{~b}$ & $4,98 \mathrm{ab}$ & $0,1577 \mathrm{ab}$ & $0,0440 \mathrm{a}$ & $0,0088 \mathrm{ab}$ & $0,0070 \mathrm{ab}$ \\
\hline 9 & $3,76 \mathrm{ab}$ & $1,25 \mathrm{ab}$ & $4,98 \mathrm{ab}$ & $0,1452 \mathrm{abc}$ & $0,0391 \mathrm{a}$ & $0,0095 \mathrm{a}$ & $0,0078 \mathrm{a}$ \\
\hline 10 & $3,82 \mathrm{a}$ & $1,17 \mathrm{ab}$ & $4,75 \mathrm{bc}$ & $0,1605 \mathrm{a}$ & $0,0406 \mathrm{a}$ & $0,0073 \mathrm{bc}$ & $0,0059 \mathrm{abc}$ \\
\hline C.V. (\%) & 6,26 & 11,41 & 9,07 & 5,58 & 7,50 & 12,99 & 25,90 \\
\hline
\end{tabular}

*Médias seguidas pela mesma letra na coluna não diferem entre si pelo teste de Tukey (P < 0,05). 1 - Testemunha; 2- Imersão de sementes em ácido sulfúrico concentrado durante 1 minuto; 3 - Imersão de sementes em ácido sulfúrico concentrado durante 2 minutos; 4 - Imersão de sementes em ácido sulfúrico concentrado durante 4 minutos; 5 - Imersão de sementes em ácido sulfúrico concentrado durante 6 minutos; 6 - Imersão de sementes em ácido sulfúrico concentrado durante 8 minutos; 7 - Imersão de sementes em ácido sulfúrico concentrado durante 10 minutos; 8 - Desponte; 9 - Escarificação com lixa d'agua ${ }^{\circ}$ 80 e 10 - Escarificação com lixa d'agua $n^{\circ} 100$.

Para Mariano et al. (2016) verificaram que em sementes de leucena a altura de plântulas não obteve diferença significativa entre escarificação com lixa $n^{0} 100$, imersão em ácido sulfúrico e, imersão em água a $80^{\circ} \mathrm{C}$, mas, encontraram o menor valor para esta característica no tratamento testemunha, fato que corrobora os resultados encontrados nesse experimento. Provavelmente grande parte da energia utilizada pela semente para romper o tegumento natural devido à dormência em sementes não tratadas (testemunha) tenha sido maior, quando comparada a energia usada nas sementes submetidas aos demais tratamentos, sendo assim, no momento do crescimento a plântula não obteve energia suficiente para expressar sua altura adequada.

Na característica diâmetro de caule Santos et al. (2013) encontraram que os maiores valores foram verificados quando utilizaram os tratamentos escarificação com lixa na extremidade oposta a micrópila e escarificação junto a micrópila das sementes de mulungu (Erythrina velutina), o que corrobora com os resultados dessa pesquisa. Desse modo, verifica-se que esses tratamentos são adequados, o que proporcionam bom desenvolvimento inicial de plântulas, fazendo com que a plântula expresse o máximo diâmetro, visto que essas espécies vegetais tem grau de parentesco próximo, devido ambas serem leguminosas. Em trabalho realizado por Nascimento et al., (2011) com sementes de murici (Byrsonima crassifólia) submetidas a diferentes tratamentos pré-germinativos, notou-se que a escarificação mecânica com lixa $n^{\circ} 80$ e, a escarificação mecânica com lixa $\mathrm{n}^{\circ} 80$ mais imersão em água destilada por 72 $\mathrm{h}$ proporcionaram os melhores resultados para o comprimento de raiz.

Segundo Araújo et al. (2012) ao avaliarem sementes de leucena quando submetidas a diferentes escarificações encontraram que a matéria seca de parte aérea e da raiz não foram obtiveram diferença estatística significativa, resultados estes que refutam os encontrados nessa pesquisa, percebe-se quando utilizou-se os tratamentos físicos observou-se os melhores resultados para essas características.

\section{CONCLUSÕES}

$\mathrm{O}$ método mais adequado para superar a dormência em sementes de leucena é o uso da escarificação com lixa d'agua $\mathrm{n}^{\circ}$ 100.

\section{REFERÊNCIAS}

ALVES, A. F.; ALVES, A. F.; GUERRA, M. E. C.; FILHO, S. M. Superação de dormência de sementes de braúna (Schinopsis brasiliense Engl.). Ciência Agronômica, v. 38, n. 1, p. 74-77, 2007.

ARAÚJO, T. V.; JOAQUIM, W. M.; BARJA, P. R. Técnicas de quebra de dormência e estudo de substratos orgânicos para produção de mudas de leucena. UNIVAP, v. 18, n. 32, p. 89100, 2012. 10.18066/revunivap.v18i32.77. 
CARDOSO, E. A.; ALVES, A. U.; CAVALCANTE, I. H. L.; FARIAS, S. G. G.; SANTIAGO, F. E. M. Métodos para superação de dormência em sementes de leucena. Ciência Agraria, v. 55, n. 3, p. 220-224, 2012. 10.4322/rca.2012.062.

CARRIJO, M. S.; DAN, H. A.; GOULART, M. M. P.; CARNEIRO, D. F.; WALKER, R.; GONÇALVES, A. H.; COSTA, A. P. Efeitos de métodos para quebra de dormência sobre a germinação de sementes de leucena. PUBVET, v. 2, n. 27, p. 277-279, 2008.

COSTA, J. N. M. N.; DURIGAN, G. Leucaena leucocephala (Lam.) de Wit (Fabaceae): invasora ou ruderal? Árvore, v. 34, n. 5 , p. $825-833,2010$. 10.1590/S0100-67622010000500008.

FERREIRA, D. F. SISVAR: um programa para análises e ensino de estatística. Symposium, Campinas, v. 6, n. 1, p. 36 41, 2008.

HALLIDAY, M. J.; PADMANABHA, J.; MCSWEENEY, C. S.; KERVEN, G.; SHELTON, H. M. Leucaena toxicity: a new perspective on the most widely used forage tree legume. Tropical Grasslands, v. 1, p. 1-11, 2013.

HERMANSEN, L. A.; DURYEA, M. L.; WEST, S. T.; WHITE, T. L.; MALASIS, M. M. Pre-treatments to overcome seed coat dormancy in Dimorphandra mollis. Seed Science \& Technology, v. 28, n. 1, p. 581-595, 2000.

LABORIAU, L. G. A germinação de sementes. Washington: Secretaria Geral dos Estados Americanos, 1983. 173p.

LUZ, G. R.; NUNES, Y. R. F. Seed germination of arboreal shrub species with different dispersal mechanisms in a Brazilian Tropical Dry Forest. In: SANCHEZ-AZOFEIFA, A.; POWERS, J. S.; FERNANDES, G. W.; QUESADA, M. (Ed.). Tropical Dry Forests in the Americas: ecology, conservation, and management. Boca Raton: CRC Press, 2013. p. 286-303.

MAGUIRE, J. D. Speed of germination and in selection and evaluation for seedling emergence and vigor. Crop Science, v.2, n.2, p.176-177, 1962. 10.2135/cropsci1962.0011183X000200020033x.

MARIANO, L. G.; SOMAVILA, A.; SILVEIRA, A. G.; SALAMONI, A. T. Análise de superação de dormência de sementes de Leucaena leucocephala e desenvolvimento inicial de plântulas. Gestão, Educação e Tecnologia Ambiental, v. 20, n. 1, p 398-404, 2016. 105902/2236117019719.

NASCIMENTO, I. L.; LEAL, C. C. P.; NOGUEIRA, N. W.; MEDEIROS, A. K. P.; CÂMARA, F. M. M. Uso de metodologias variadas na superação de dormência tegumentar de sementes de murici. Verde, v. 6, n. 3, p. 226-230, 2011.

OLIVEIRA, A. B.; MEDEIROS FILHO, S. Influência de tratamentos pré-germinativos, temperatura e luminosidade na germinação de sementes de leucena. Ciências Agrárias, v. 2, n. 4, p. 268-274, 2007.
OLIVEIRA, A. B. Germinação de sementes de leucena (Leucaena leucocephala (Lam.) de Wit.), var. K-72. Biologia e Ciências da Terra, v. 8, n. 1, p. 166-172, 2008.

OLIVEIRA, A. B. Influência de tratamentos pré-germinativos, temperatura e luminosidade na germinação de sementes de leucena (Leucaena leucocephala (Lam.) de Wit.), cv. Cunningham. Caatinga, v. 22, n. 2, p. 132- 138, 2009.

OSECHAS, D.; BECERRA, L.; RODRIGUEZ, I. Uso de Leucaena leucocephala L. como recurso forrageiro em fincas doble propósito del estado Trujillo, Venezuela. Agricultura Andina, v. 14, n. 1, p. 49-58, 2008.

RIBEIRO, V. V.; BRAZ, M. M. S.; BRITO, N. M. Tratamentos para superar a dormência de sementes de tento. BIOTEMAS, v. 22 , n. 4, p. 25-32, 2009.

PEREZ, S. C. J. G. A. Envoltórios. In: FERREIRA A. G.; BORGHETTI, F. (Org.). Germinação do básico ao aplicado. Porto Alegre: Artmed, 2004. p. 125-134.

SANTOS, L. W.; COELHO, M. F. B.; MAIA, S. S. S.; SILVA, R. C. P.; CÂNDIDO, W. S.; SILVA, A. C. Armazenamento e métodos para a superação da dormência de sementes de mulungu. Semina: Ciências Agrárias, v. 34, n. 1, p. 171-178, 2013. 10.5433/1679-0359.2013v34n1p171.

SILVA, M. A.; SANTOS, M. V. F.; LIRA, M. A.; DUBEUX JÚNIOR, J. C. B.; SILVA, D. K. A.; SANTORO, K. R. LEITE, P. M. B. A.; FREITAS, E. V. Qualitative and anatomical characteristics of tree-shrub legumes in the Forest Zone in Pernambuco state, Brazil. Revista Brasileira de Zootecnia, v. $41, \quad$ n. $12, \quad$ p. $2396-2404, \quad 2012 . \quad \underline{10.1590 / \mathrm{S} 1516-}$ 35982012001200003 .

TELES, M. M.; ALVES, A. A.; OLIVEIRA, J. C. G.; BEZERRA, A. M. E. Métodos para quebra da dormência em sementes de Leucena (Leucaena leucocephala (Lam.) de Wit. Revista Brasileira de Zootecnia, v. 29, n. 2, p. 387-391, 2000. $\underline{10.1590 / \mathrm{S} 1516-35982000000200010 .}$. 